sible for the project scans the paper for pertinent articles. The file name is written by the title for each selected article and the keywords are underlined. If additional terms are necessary these are written down as well. The number of keywords varies from article to article but we aim for a maximum of 3-6. As a rule each article is assigned to one file. However, at times the nature of an article is such that it may be included in additional files. A student employed 8-10 hours perweek takes the annotated newspapers and inputs the data via Pro-Cite onto a $31 / 2$-inch disk. Once a week these files are merged with the master file on the Bernoulli cartridge. The master file is then copied.

As knowledge of the database has spread, library patrons often approach the main reference desk specifically requesting a newspaper search. Others are identified during the reference interview. In either case a brief search request form is completed and the patron is asked to return in 24 hours for the results. With the database and equipment located two floors above the reference desk we have found the one-day delay necessary. The searcher retains a copy of the search for statistics but also frequently notes search terms and results for possible future reference. When several members of an English class request information on the same topic this last step has been particularly useful. The printout received by the patron contains all the information in the Pro-Cite record. With truncation and Boolean searching possible on Pro-Cite, our suc- cess rate has been affected more by the content of the database than anything else.

Two areas of difficulty have arisen over the past four years: documentation and terminology. Current documentation covers the technical aspects of the database (record format, merging, etc.). We are preparing to write formal guidelines for the indexing process itself such as the selection of keywords, and the inclusion criteria for articles. Our second problem area is also being resolved. Because we rely on keyword access to the index it is important to maintain keyword uniformity. However, the papers have varied their terminology over time and that is reflected in the database. An excellent example of this is an important local highway project. At times this has been referred to as the Route 460 bypass, the Route 460 corridor, and the direct link. To resolve these variations a list of keywords will be produced for each file. Uniformity of terms will be re-established, typographical errors corrected, and a new list of keywords produced. The indexer will be able to refer to the thesaurus while selecting keywords to assure consistency. Terms will be added, deleted, or changed as necessary. Those records having terms which are deleted or changed will be edited.

Our newspaper index utilizing Pro-Cite provides timely access to local papers. By giving a unique twist to Pro-Cite's capacity to handle large amounts of bibliographic information, we have met both of the objectives identified four years ago.

\title{
Students and support staff on the reference desk
}

\author{
By Lynn Westbrook
}

Coordinatorfor Reference and Instruction

Undergraduate Library, University of Michigan

As yet another library school dissolves, the need for quality practicum opportunities for students at the remaining institutions grows. As various groups within ALA wrestle with the thorny problem of recruiting a diverse population of graduate library science students, the need for meaningful jobs during graduate school becomes a significant piece of the problem for many potential students who cannot afford to shelve books while getting a library science degree when they could be doing laboratory work while getting a pharmacy degree.

These situations share a common, if partial, solu- tion which provides major benefits for those libraries able to practice it. By creating and publicizing a well-crafted reference and/or BI training program, libraries provide four contributions to the profession: excellent practical experience for students who can get course credit for library work; the opportunity for working library science students to gain the type of expertise which will give them a real boost in their first job hunt; the opportunity for undergraduates to experience and consider the possibility of library science as a profession; and valuable assistance for their own departments. 


\section{When you can measure}

\section{what you are speaking about, and express it in numbers, you know something about it.}

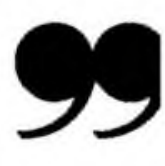

William Thomson, Lord Kelvin

\section{ACRL University Library Statistics 1987-88}

compiled by Robert E. Molyneux

Reports statistics on collections, personnel, and expenditures for 100 non-ARL university libraries. "Decision makers need valid and reliable data. The title provides such data for academic libraries," Library Journal said of the last edition. 1989. 80p. ISBN: 0-8389-7288-8. $\$ 49.95$; ACRL member $\$ 29.95$

Special offer! Buy both the print book and the machine readable data for only $\$ 99.95-$ a ten dollar savings ( $\$ 66.95$ for ACRL members). Use order number 0-8389-7311-6.

\section{ACRL Academic Library Statistics, 1978/79-1987/88 (Diskettes)}

prepared by Robert E. Molyneux Machine-readable diskettes accompanied by a detailed user guide, contain data from the five editions of a series of academic library data published by ACRL (1978-79, 1981-82, 1983-84, 1985-86, 1987-88). The data are presented in three formats: ASCII, sAS data sets, and "DIF" (data interchange format) which can bring the data into Lotus 1-2-3. The package contains four MS-Dos 5.25 " $360 \mathrm{~K}$ diskettes and two MS-Dos 3.5" 720K floppy diskettes.

1989. ISBN: 0-8389-7310-8. \$59.95; ACRL member $\$ 47.95$.
Association of College

A Division of the

American Library Association c/o ALA Publishing Services, Order Deparment, 50 E. Huron St., Chicago, IL 60611; 312-944-6780

Call toll-free: 800-545-2433 (U.S.): 800-545-2444 (III.); 800-545-2455 (Canada). FAx: 312-440-9374 
At the University of Michigan's Undergraduate Library, this type of program has been in practice for years for three groups of students. Each year as part of the Peer Information Counseling program (a minority student support service) about nine undergraduate students are trained to work on the reference desk with full-time staff. ${ }^{1}$ In addition, each semester the reference department accepts up to four library science students who work a minimum of six hours per week on the reference desk (plus projects) for course credit. Finally, each year about five library science students are recruited to serve as paid reference assistants on the reference desk.

This past year the general training materials were expanded, supplemented, and revised in a variety of areas. A Training Modules Taskforce examined, codified, and strengthened the reference training program used to prepare all students for their work on the desk. The resulting material covers six two-hour sessions as well as a supplemental series of subject-oriented seminars. In addition, a new training program was created in the area of bibliographic instruction. Available only to library science students, this seven-part program is offered when at least two self-selected students are willing to commit to the work entailed which culminates in each student teaching at least two of the basic psychology classes, the most commonly taught BI session. Finally, through contacts with the School of Library and Information Science, materials were prepared to assist in recruiting students to the SILS program and then, when possible, to the Undergraduate Library. By distributing descriptions of the jobs and field experiences available to potential students, it is hoped that not only will more students consider library science as a possible profession but that those who do choose to come will at least consider the advantages of graduating with practical experience. ${ }^{2}$

Libraries in different situations may find some possibilities for similar programs. If students, whether undergraduate or non-library science graduate, are hired for non-desk work in the reference department, consideration may be given to their potential recruitment into the profession. A reasonable cost/benefit ratio might be obtained, for example, by training them to work the quieter shifts on the desk while an on-call librarian uses that time

${ }^{1}$ For more information on the Peer Information Counseling program, see Barbara MacAdam and Darlene Nichols, "Peer Information Counseling at the University of Michigan Undergraduate Library," Journal of Academic Librarianship 14 (May 1988): 80-81.

${ }^{2}$ For copies of the training program outlines and recruitment material, contact the author. for other duties. Perhaps they will get a little less shelving done each week, but the trade-off might be worth it as there might be less turnover among shelvers who are now more satisfied with their work. Support staff might also benefit from such an arrangement.

Institutions with strong education departments may find it possible to arrange for undergraduates with a media/library concentration to have a practicum in the library. As they work on the reference desk, these students may develop an appreciation for or even an interest in library science.

Libraries that firmly refuse to allow students on the reference desk, alone or with professionals, may consider the advantages of the microcomputer center model for student workers. In this scenario students do not answer all reference questions; instead they are carefully trained on a single type of tool. For example, any library with an online catalog may well find that during the busy afternoon hours or in the rush of Monday night work, it can be invaluable to have a well-trained student at the workstations who can do anything from fixing the printer to explaining the basics of a title search.

Reference areas with CD-ROMs, Wilsearch, and InfoTrac may find that by training a few selfselected technical services support staff members each year, they have a regular core of people eager to assist the public for a few hours each week during the busiest part of the term. Their supervisors in such areas as cataloging, acquisitions, and serials may find that this variety of experience allows them to keep their student workers and support staff longer. And the profession at large may find that a few more good minds have begun to consider library science as a professional career.

Careful deployment of limited resources is a given in every well-managed reference department. Contributing to and recruiting the best for the profession is an often intangible goal. Wellcrafted, ongoing development programs for support staff are difficult to create and maintain. ${ }^{3}$ No single effort will meet all of these needs, but an entrepreneurial outlook in reference training may be of significant value.

${ }^{3}$ For further reading on training, see: Sheila Creth, Effective On-the-Job Training: Developing Human Resources (Chicago: American Library Association, 1986); Painlessly Preparing Personalized Training Programs (Berkeley, Calif.: University of California General Library, 1982); Margaret Blanksby, Staff Training: A Librarian's Handbook (Newcastle-under-Lyme, Eng.: Association of Assistant Librarians, 1988); Harvey Sager, "Training Online Catalog Assistants," C dRL News 11 (December 1986): 721-23; and Beth Woodward, et al., "Training Professionals for Reference Service," Reference Librarian 16 (Winter 1986): 233-54. 